\section{Meetings and Courses}

Annual Courses

Title: Courses on Current Issues in Sexual and Reproductive Health organised by The Margaret Pyke Memorial Trust. Details: See display advertisement on inside back cover.

\section{November 2006}

Title: National Chlamydia Screening Programme Annual Conference 'New Frontiers'. Venue: Mermaid Theatre, Blackfriars, London, UK. Details: The NCSP aims to implement opportunistic chlamydia screening for men and women aged under 25 years. The programme is currently being rolled out to all PCTs in England with the aim of national coverage by March 2007. The conference organisers hope that all those actively involved in implementation of the programme will be able to attend this conference. The conference will provide a forum for discussion of issues of common interest, an opportunity to showcase innovative ideas and offer valuable networking opportunities. The conference is free to those directly involved in the planning or delivery of the NCSP. Registration is now open. Information: www.hpa-events.org/ncspconference.

23-24 November 2006

Title: FFPRHC Current Choices Conference. Venue: The Royal Society of Medicine, London, UK. Details: See display advertisement below.

\section{February, 1-2 March 2007}

Title: Potential Instructing Doctors Course. Venue: Chancellor's Conference Centre, Manchester, UK. Details: An annual residential course for which applications are invited from doctors who are an accredited DFFP. Accreditation: FFPRHC accreditation applied for. Information: Ann Conti, Regional Training Department, 63-65 Palatine Road, Manchester, M20 3LJ, UK. Tel: +44 (0) 161434 8629. Fax: +44(0) 161448 1889. E-mail: ann.conti@ manchester.ac.uk.

\section{5-19 April 2007}

Title: 18th World Congress of the World Association for Sexual Health, 1st World Congress for Sexual Health. Venиe: Sydney, Australia. Details: See display advert on inside back cover.
25 May 2007

Title: Induced Abortion: Best Practice. Venue: The Royal Society of Medicine, London, UK Details: The latest advances in clinical and service delivery aspects of medical and surgical abortion will be presented, with an international perspective. Accreditation: CPD 5 credits applied for. Information: Helen Barrington, The Royal Society of Medicine, 1 Wimpole Street, London W1G 0AE, UK. Tel: +44 (0) 207290 2984. Fax: +44(0) 207290 2989. E-mail: sexmed@ rsm.ac.uk.

There is a charge of $£ 50.00+$ VAT for each meeting/course publicised in this section of the Journal. This will guarantee inclusion in the issue requested. For guaranteed inclusion in the January 2007 issue all course details should be with Sarah Monger by 10 November 2006. For a booking form please contact Sarah Monger at PMH Publications, PO Box 100, Chichester, West Sussex PO18 8HD, UK. Tel: +44 (0) 1243 816689. Fax: +44 (0) 1243567456 E-mail: sarah.monger@pmh.uk.com.
THE FACULTY OF FAMILY PLANNING AND REPRODUCTIVE HEALTH CARE of the Royal College of Obstetricians \& Gynaecologists

\section{Forthcoming Meeting The Current Choices Conference}

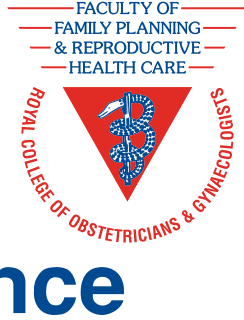

will take place at The Royal Society of Medicine, London, UK on Thursday 23 November and Friday 24 November 2006

The programme will include:

- Intrauterine devices $\bullet$ The evidence-based approach $\bullet$ Common clinical challenges $\bullet$ Depo-Provera interactive session: all you want to know $\bullet$ Implementing LARC guidelines $\bullet$ Making contraceptive choices and taking risks - Choice and decision-making in sexual health $\bullet$ Risk-taking behaviour and unplanned pregnancy $\bullet$ The influence of the media on choices and risks in reproductive health $\bullet$ Contraception of the past and future

- Looking back: a historical review • Hormonal contraception: new developments • Office gynaecology - Investigating and managing secondary amenorrhoea $\bullet$ Modern management of menorrhagia $\bullet$ Sexual health in middle youth $\bullet$ Common vulvul disorders • Evidence-based preconception counselling $\bullet$ Current patterns of adoption in the UK $\bullet$ Middle-aged pregnancy: private grief or public health disaster? $\bullet$ Debate: is the male menopause underdiagnosed or misunderstood?

A trade exhibition will also be held in conjunction with the meeting.

Please register online: www.ffprhc.org.uk

For further information please contact the FFP and RHC Secretariat at:

Current Choices 2006, c/o Meeting Makers, Jordanhill Campus, 76 Southbrae Drive, Glasgow, G13 1PP. Tel: +44 (0) 1414341500 Fax: +44 (0) 1414341519

E-mail: currentchoices2006@meetingmakers.co.uk

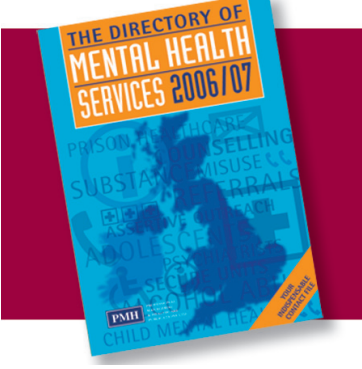

Directory of Mental Health Services

A comprehensive guide to the mental health professionals and services within the UK - the ideal desk reference for a nurse or anyone working in this sector.

Find out more at www.directoryMHS.co.uk or telephone 01243576444 